
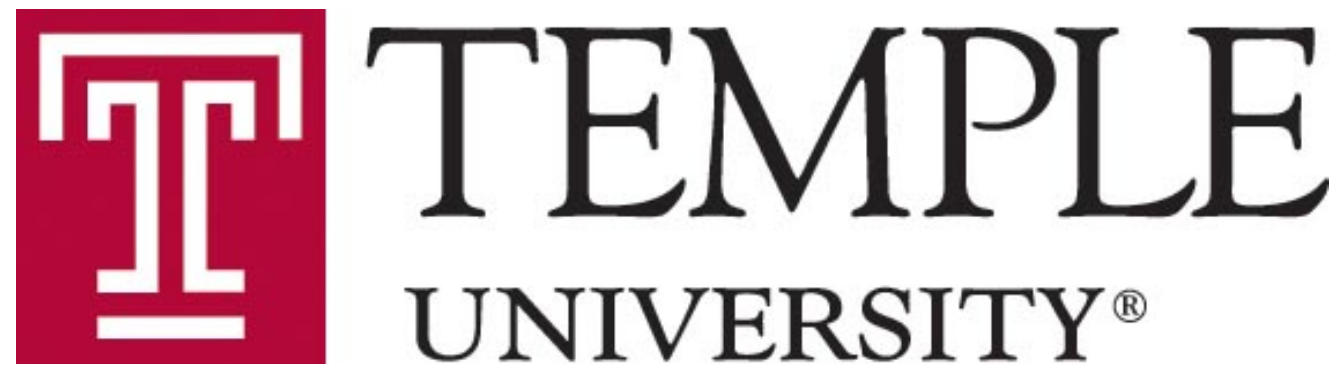

\title{
Who Pays the High Health Costs of Older Workers? Evidence from Prostate Cancer Screening Mandates
}

\author{
by \\ James Bailey \\ Department of Economics \\ DETU Working Paper 13-02
}

September 2013

1301 Cecil B. Moore Avenue, Philadelphia, PA 19122

http://www.cla.temple.edu/economics/faculty/detu-working-paper-series/ 


\title{
Who Pays the High Health Costs of Older Workers? Evidence from Prostate Cancer Screening Mandates
}

\author{
James Bailey \\ Temple University, Department of Economics. 1301 Cecil B. Moore Avenue, Ritter Annex 834, Philadelphia, PA 19122, \\ United States.JBailey@temple.edu
}

\begin{abstract}
Abstract: Between 1992 and 2009, 30 US states adopted laws mandating that health insurance plans cover screenings for prostate cancer. Because prostate cancer screenings are used almost exclusively by men over age 50, these mandates raise the cost of insuring older men relative to other groups. This paper uses a triple-difference empirical strategy to take advantage of this quasi-random natural experiment in raising the cost of employing older workers. Using IPUMS data from the March Supplement of the Current Population Survey, this paper finds that the increased cost of insuring older workers results in their receiving $2.8 \%$ lower hourly wages, being $2 \%$ less likely to be employed, and being $0.7 \%$ less likely to have employer-sponsored health insurance.
\end{abstract}

Keywords: Older Workers; Prostate Cancer Screening; Health Insurance; Mandated Benefits; Triple-Difference

JEL: J20, J30, I13

Acknowledgments: Thanks to Douglas Webber, Anna Chorniy, Eleanor Lewin, Nathan Blascak, Jason Keegan, and the Temple University Dissertation Seminar for helpful comments.

\section{Introduction}

Prostate cancer mandates are state laws that require most private health insurance plans to cover screening tests for prostate cancer. These mandates are now in place in 29 US states. There has been a steady growth in the number of prostate cancer mandates since Delaware and Georgia passed the first laws in 1992. This paper uses a difference-in-difference-in-difference (henceforth triple difference or DDD) strategy to estimate the effects of these mandates on the labor outcomes of older men. Prostate cancer screening is used exclusively by men, and almost exclusively by men over age 50 . Therefore, insurance companies and employers know that the cost of this mandate will be generated by one easily identifiable subgroup, rather than by the whole population, and they can be expected to frame their responses to the mandate accordingly. 
Prostate cancer mandates provide a quasi-random natural experiment of increasing health costs for employers. This gives an opportunity to study how workers and employers react to the fact that older workers generally have higher health costs. Previous work has found that the relatively poor health of older workers adversely affects their labor market outcomes both directly (Bound et al. (1999)) and through increased health insurance costs paid by employers (Scott et al. (1995)).

This paper uses 1990 to 2009 data on labor market outcomes and controls from the Integrated Public Use Microdata Series compilation of the March Current Population Survey (IPUMSCPS), a dataset with approximately 200,000 individual-level observations per year. The particular labor market outcomes studied are employment, hourly wages, and whether or not an individual has employer-provided health insurance. I find that labor markets react strongly to the increased health costs of older workers, resulting in lower levels of money wages, employment, and employer-based health insurance among the older men that prostate cancer screening mandates were intended to help.

Section 2 gives more information on prostate cancer mandates, health insurance mandates in general, and the medical side of prostate cancer. Section 3 describes the data and the empirical strategy of triple-difference estimation. Section 4 gives the econometric results and discusses their robustness and implications. Section 5 concludes.

\section{Background}

\subsection{Health Insurance Mandates}

Health insurance mandates are common at the state level in the United States, and are applied to many benefits besides prostate cancer screening. Many other specific treatments or conditions receive mandated coverage, from maternity care to infertility treatments to diabetes. Laws mandating that health insurance cover specific treatments or conditions are known as benefit mandates. Other types of mandates may require insurance to cover certain types of providers, such as chiropractors, or certain types of beneficiaries, such as grandchildren. This paper follows most academic work in focusing on benefit mandates, which are the most common type. Industry organizations such as the Council for Affordable Health Insurance and the Blue Cross Blue Shield Associations release annual reports tracking which mandates are in force in each state, the most recent reports being Laudicina et al. (2011) and Bunce and Wieske (2011). The number of mandates in force in the average state has greatly increased over the past 40 years. According to the Council for Affordable Health Insurance, the average number of mandates in each state has gone from 0 in 1960, to 17 in 1992, to 45 in 2011. Every year more mandates are passed, while they are almost never repealed.

There has been a fair amount of academic work on health insurance mandates, which is summarized in the survey articles by Jensen and Morrisey (1999) and Monheit and Rizzo (2007). 
One basic effect of mandates often predicted by these papers is an increase in overall insurance premiums, as treatments that were formerly paid out-of-pocket are now paid using insurance, while moral hazard increases total use of the service. Kowalski et al. (2008), LaPierre et al. (2009), and Gohmann and McCrickard (2009) test this hypothesis in the market for individual insurance. Kowalski et al. (2008) and Gohmann and McCrickard (2009) find that mandates tend to cause statistically significant increases in premiums, while LaPierre et al. (2009) find they do not. Gohmann and McCrickard (2009) and LaPierre et al. (2009) find large variations in the effects of different mandates, with some causing large increases in premiums while others cause premiums to decrease. Bailey (2013) tests the effect of mandates on premiums for employerbased group health insurance (which represents the vast majority of the private insurance market), finding that the average mandate causes a statistically significant increase in premiums of 0.44 $1.11 \%$. Bunce and Wieske (2011) use actuarial data to estimate the cost of each mandate, finding that some mandates lead to insurance cost increases of over 5\%, while most mandates (including prostate cancer screening) directly increase costs by less than $1 \%$. It is important to keep in mind, however, that each paper cited above estimates the effect of mandates on the premium for an average person, rather than analyzing how mandates could have different costs for different groups.

Most other academic work on mandates has examined their effects on the labor market, starting with Summers (1989). If mandates result in higher insurance premiums, then employers who offer health insurance may reconsider their compensation packages. They may stop offering health insurance, change the composition of insurance plans, or reduce other forms of compensation, such as wages. Gruber (1994b) found that unemployment did not rise after the passage of five particularly costly mandates. He speculated that the mandates did not actually increase the proportion of plans offering the mandated treatments, due to mandate exemptions and a high proportion of plans already offering the treatments. Because of the Employee Retirement Income Security Act of 1974 (ERISA), state mandates do not apply to self-insured firms, which cover about half of all workers.

Kaestner and Simon (2002) also found that the average mandate does not have a statistically significant effect on labor market outcomes for the average person. Van der Goes et al. (2011), by contrast, found that the average mandate reduces the chance that an individual has employerprovided health insurance by $0.2 \%$, and Jensen and Gabel (1992) found that mandates are a major reason that some firms do not offer health insurance. Buchmueller et al. (2011) found that a mandate for employers to offer insurance to full-time workers did not affect wages but did cause employers to hire more mandate-exempt part-time workers. Cseh (2008) found no labor market consequences for mental health parity mandates, which are targeted at a particular group but not one identifiable to employers. Meer and West (2011) argue that those looking for labor market effects of mandates on subgroups like small businesses suffer from small sample bias, 
even in large datasets like the CPS, leading to high standard errors. In summary, there is mixed evidence that the average health insurance benefit mandate has significant effects for the average person.

The evidence that mandates affect specific identifiable groups is much stronger. Gruber (1994a) found that the cost of mandated maternity care benefits was passed on in its entirety in the form of lower wages for women aged 20-40. Lahey (2012) found that infertility treatment mandates resulted in lower wages and labor supply for women aged 28-42. The cost of a mandate may be too small to notice if it is spread out over all insured people, but it can be significant if it is passed on to one relatively small and identifiable demographic group.

\subsection{Prostate Cancer Screening}

The basic facts about prostate cancer are well-summarized by the most recent report of the United States Preventative Services Task Force (USPSTF), an independent expert body within the Agency for Health Care Research and Quality. They state that

"Prostate cancer is the most commonly diagnosed non-skin cancer in men in the United States, with a lifetime risk for diagnosis currently estimated at 15.9\%. Most cases of prostate cancer have a good prognosis, even without treatment, but some are aggressive; the lifetime risk of dying of prostate cancer is $2.8 \%$. Prostate cancer is rare before age 50 years and very few men die of prostate cancer before age 60 years. Seventy percent of deaths due to prostate cancer occur after age 75 years."

The most common screening test is the Prostate-Specific Antigen (PSA) test, which tests blood serum. Digital Rectal Examinations (DRE) are also sometimes employed. The USPSTF gives the PSA test a grade D recommendation, meaning they recommend against it. Their methodology considers only medical harms and benefits, not financial costs. According to USPSTF (2012), "There is adequate evidence that the benefit of PSA screening and early treatment ranges from 0 to 1 prostate cancer deaths avoided per 1000 men screened... no study found a difference in overall or all-cause mortality." This possible benefit is weighed against the potential harm incurred from screening and treatment. Surgery and radiation used to treat prostate cancer cause enough morbidity and mortality that the USPSTF finds that "there is convincing evidence that PSA-based screening for prostate cancer results in considerable overtreatment and its associated harms."

It is an odd and concerning fact that people in the United States spend so many resources on, and in fact mandate insurance coverage for, medical care that may bring no net benefit. The argument of this paper, however, does not rely on the still-debated claim that prostate cancer screening has no net medical benefit. The econometric strategy used to test the labor market effect of these mandates depends on two facts about prostate cancer screening. One is that it is 
primarily used by one demographic group, men over age 50 . This point should be beyond dispute: prostate cancer affects only men, the vast majority of prostate cancer diagnoses and deaths are in men over age 50, and even the more pro-PSA-testing guidelines from the American Cancer Society recommend possible screening only for men over age 50 . The other fact about prostate cancer screening necessary for this paper's argument is that screening is expensive enough for insurers and employers to notice and care about.

This may not be so obvious, since the PSA test is simple blood work, and Medicare only pays about $\$ 30$ per test. However, the test can lead to additional treatments that would not have occured otherwise. According to USPSTF (2012), "Over 10 years, approximately 15\% to 20\% of men will have a PSA test result that triggers a biopsy." Mitchell (2012) finds that in 2005 Medicare paid approximately $\$ 900$ per prostate biopsy (including pathology lab services). This screening also leads to prostate cancer being treated earlier and more often; according to USPSTF (2012), "From 1986 through 2005, PSA-based screening likely resulted in approximately 1 million additional U.S. men being treated with surgery, radiation therapy, or both compared with the time before the test was introduced". This makes for an additional 50,000 cases of prostate cancer being treated every year. According to Jacobs et al. (2012), about 200,000 men are diagnosed with prostate cancer every year in the US, making screening-induced treatments $1 / 4$ of the total.

According to Surveillance Epidemiology and End Results (SEER) data summarized by Howlader et al. (2013) the 50-64 age group accounts for $40 \%$ of prostate cancer diagnoses. Assuming that the age of the screening-induced cases matches that of the general prostate cancer population, this means 20,000 men age 50-64 are diagnosed with prostate cancer annually as a result of PSA screening. Because prostate cancer is so slow-growing, men commonly have the disease for decades before dying of another cause. From the perspective of an employer, screening may result in payments for surgery or radiation treatment now that otherwise would have been put off for years, often past retirement. Roehrig et al. (2009) estimate that in 2005, medical total spending related to prostate cancer treatment was $\$ 6.8$ billion, or $\$ 34,000$ per new prostate cancer patient. Each year PSA testing leads to 20,000 addition prostate cancer diagnoses among men aged 5064 ; this represents $0.1 \%$ of the age group, making for an expected cost of $\$ 34000 * 0.001=\$ 34$. Even combined with the costs of biopsies and and PSA tests, expenditures on prostate cancer are relative low.

This suggests that the direct monetary costs of prostate cancer may be dominated by lost time: absences due to attending screening and treatment, or early retirements due to receiving a cancer diagnosis.

\subsection{Prostate Cancer Mandates}

Figure 1 shows when each state passed its prostate cancer mandate; blank states have not passed any prostate cancer mandate as of 2013. Figure 2 shows the number of US states with 


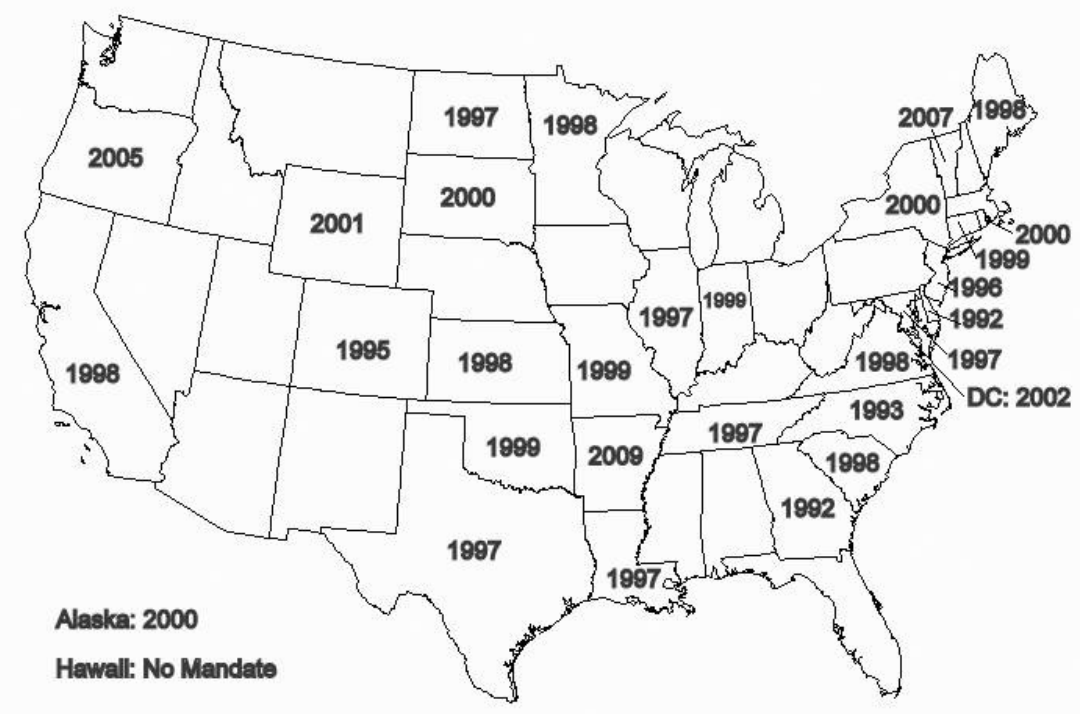

prostate cancer mandates in force over time. The steady upward trend is clear, with rapid growth in the mid-1990s. There is some variation in the specific language used in each state's mandate law. Most states mandate coverage for men over age 50 and for men over age 40 who are in highrisk categories, while some simply mandate coverage for everyone. Many states specifically mention that they are mandating the Prostate-Specific Antigen test, some specify this as well as another test, and some do not specify the screening technique. Given that prostate cancer screening is mainly sought by men over age 50 in any case, this variation in state laws does not seem to be enough to require different codings of the mandate variable in the main regressions.

\section{Data and Identification Strategy}

\subsection{Data Sources}

Data on the passage of mandates was gathered from several sources. The Blue Cross Blue Shield Association releases an annual report, "State Legislative Healthcare and Insurance Issues," which includes information on which health insurance benefit mandates are in force in each state. The National Council of State Legislatures maintains a database of states that have passed prostate cancer screening mandates, with a description of the specific components of each state 


\section{States with Prostate Cancer Mandates}

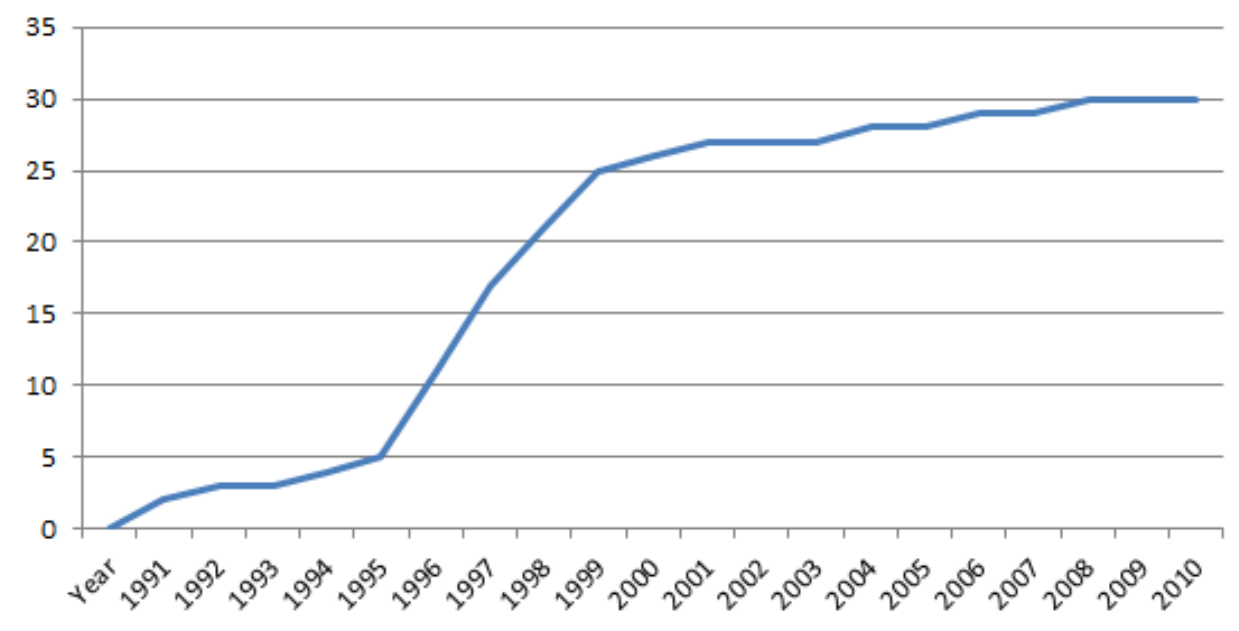

Figure 2: Number of States with Prostate Cancer Mandates by Year

law. The initial coding of the dummy variable for the passage of mandates was based on these two sources. When the BCBSA and NCSL were in conflict, Lexis Nexis was used to find the actual text of the state law and determine how to code the state.

All other data is from the Integrated Public Use Microdata Series release of the March Current Population Survey, compiled by King et al. (2010). There are 3.5 million observations covering every state and the District of Columbia from 1990 to 2009. Of these, 99,862 observations cover individuals most affected by the mandates (men between 50 and 64 years of age who live in states and years where a mandate is in effect). All three dependent variables are from IPUMS: employment, hourly wages, and a dummy for whether individuals have employer-provided health insurance. The health insurance and employment variables come directly from IPUMS. Hourly wages are imputed from other IPUMS variables by dividing total annual income by hours worked per week and weeks worked per year, and adjusting for inflation using the Consumer Price Index. Wage and health insurance regressions drop the self-employed and those with no income. The natural log of hourly wages is used for the regressions so that the coefficients can be interpreted as percentage changes.

Control variables include dummies for individual's age (ageDum $36_{i}-$ ageDum64 $\left._{i}\right)$, race ( white $_{i}$

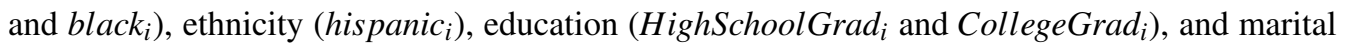
status $\left(\right.$ married $\left._{i}\right)$. The hourly wage and employer-based insurance regressions also control for job characteristics: the size of the firm $\left(\right.$ SmallFirm $_{i}$ and MidFirm $\left._{i}\right)$ and whether the worker is in a union $\left(\right.$ union $\left._{i}\right)$. The independent variables of interest for triple-difference regression are 
dummy variables generated from the IPUMS data: these include a dummy for whether an individual is male $\left(\right.$ Male $\left._{i}\right)$, a dummy for whether he is over age $50\left(\right.$ AgeGroup $\left._{i}\right)$, and a dummy for whether his state has a prostate cancer mandate in effect $\left(\right.$ Mandate $\left._{s t}\right)$. The way that these variables and the interactions between them are used for triple-difference regression is explained in the next section.

\subsection{Triple-Difference Estimation}

The primary treatment group for prostate cancer screening mandates is men over age 50 in states that have passed mandates. In a DDD regression the control groups are represented by double interaction terms such as Male $_{i} * A_{\text {AgeGroup }}$, and the treatment group of men over age 50 in states with mandates is represented by the triple interaction term Mandate $_{s t} *$ AgeGroup $_{i} *$ $M_{a l e}$. The treatment effect estimated is simply the coefficient of the triple interaction term.

The basic DDD regression equation is given by:

$$
\begin{aligned}
Y_{i t} & =\beta_{1} \text { Mandat }_{s t} * \text { AgeGroup }_{i} * \text { Male }_{i}+\beta_{2} \text { Mandate }_{\text {st }} * \text { Male }_{i} \\
& +\beta_{3} \text { Mandate }_{\text {st }} * \text { AgeGroup }_{i}+\beta_{4} \text { Male }_{i} * \text { AgeGroup }_{i}+\beta_{5} \text { Mandate }_{s t} \\
& +\beta_{6} \text { Male }_{i}+\beta_{7} \text { AgeGroup }_{i}+\beta_{8} X_{i}+\theta_{t}+\sigma_{s}+\varepsilon_{s t i}
\end{aligned}
$$

Where $Y_{i t}$ is a variable measuring the outcomes of individual workers. Three different dependent variables $Y_{i t}$ are used in separate regressions: the natural log of hourly wages, a dummy indicating whether the individual is employed, and a dummy indicating whether the individual has employer-sponsored health insurance. The subscript $i$ refers to individuals, $s$ refers to states, and $t$ refers to years. Mandate $s t$ is a dummy variable that is equal to 1 in states and years where mandates are in force and equal to 0 otherwise. AgeGroup $i$ is a dummy variable set to 1 for individuals between 50 and 64 years old, and Male $e_{i}$ is a dummy set to 1 for men. $X_{i}$ is a vector of control variables that can be observed for individuals. These controls include measures of age, race, ethnicity, education, and marital status. Controls in the wage and insurance regressions also include firm characteristics. $\theta_{t}$ indicates fixed effects for each year, and $\sigma_{s}$ indicates fixed effects for each state. The coefficient $\beta_{1}$ gives the DDD estimate of the treatment effect, the change in the dependent variable for men over age 50 in states with mandates.

\section{Results}

Table 1 shows the results of the three main triple-difference regressions. Male $*$ AgeGroup $*$ Mandate is the estimate of the treatment effect on the main treatment group. Its coefficients represent the effect of mandates on the hourly wages, employment, and chance of having employerprovided health insurance for men aged 50 to 64 . Each coefficient can be interpreted as a per- 


\begin{tabular}{cccc}
\hline & $\ln ($ HourlyWage $)$ & Employed & Employer Insures \\
\hline Male $*$ AgeGroup $*$ Mandate & $-0.028^{* * *}$ & $-0.020^{* * *}$ & $-0.007^{* * *}$ \\
& $(0.010)$ & $(0.006)$ & $(0.003)$ \\
Male $*$ AgeGroup & $0.055^{* * *}$ & $-0.030^{* * *}$ & $0.011^{* * *}$ \\
& $(0.005)$ & $(0.004)$ & $(0.002)$ \\
Male $*$ Mandate & $-0.018^{* *}$ & $0.013^{*}$ & -0.002 \\
& $(0.006)$ & $(0.007)$ & $(0.002)$ \\
AgeGroup $*$ Mandate & -0.001 & $0.021^{* * *}$ & $0.013^{* * *}$ \\
& $(0.007)$ & $(0.004)$ & $(0.002)$ \\
Mandate & 0.013 & $-0.007^{*}$ & $-0.007^{* *}$ \\
& $(0.0121)$ & $(0.004)$ & $(0.003)$ \\
AgeGroup & $0.225^{* * *}$ & $-0.313^{* * *}$ & $-0.053^{* * *}$ \\
& $(0.019)$ & $(0.005)$ & $(0.005)$ \\
Male & $0.271^{* * *}$ & $0.131^{* * *}$ & $0.015^{* * *}$ \\
& $(0.007)$ & $(0.004)$ & $(0.002)$ \\
State Fixed Effects & yes & yes & yes \\
Year Fixed Effects & yes & yes & yes \\
Observations & 803,409 & $1,299,581$ & 605,585 \\
\hline
\end{tabular}

Table 1: Basic Estimates of the Effect of Prostate Cancer Screening Mandates on labor Market Outcomes *Indicates p-values less than $0.10 * *$ Indicates p-values less than $0.05 * * *$ Indicates p-values less than 0.01; Values in parentheses are robust standard errors clustered by state. The coefficients for $\ln$ (Hourly Wage) are the results of an Ordinary Least Squares regression. The numbers reported for Employment and Employer Insurance are the marginal effects from a Logit regression, since the dependent variables are binary. Coefficients of demographic control variables are not shown (these include measures of age, race, ethnicity, education, and marital status for all regressions, as well as firm size and union membership in the wage and insurance regressions). The sample used is Americans aged 35-64. Person-level probability weights were used in all regressions to account for sampling bias.

centage change; for instance, the -0.028 coefficient for log wages can be interpreted as mandates causing a $2.8 \%$ reduction in the hourly wages of men over age 50 .

The triple-difference regression estimates for the effect of prostate cancer mandates on the labor market outcomes of older men, therefore, are as follows: after the passage of a prostate cancer mandate, hourly wages decrease $2.8 \%$, employment decreases $2.0 \%$, and the chance of having employer-provided health insurance decreases $0.7 \%$. Each result is significant at the $1 \%$ level. By contrast, the coefficient Mandate $_{s t}$ gives an estimate of the effect of mandates on the general population. This effect is estimated to be much smaller and less significant.

Only data on individuals aged 35-64 was used in these regressions. Workers under 35 may not be a close control group for those over fifty, differing in unobserved ways. Individuals over age 64 have access to Medicare, so changes in the private insurance market will have a less clear effect 
on them. However, a robustness check described in section 4.2 shows that the results remain significant with various specifications of age. Self-employed workers are not included in the wage and insurance regressions. The data used begins in 1990, two years before the first mandate was passed, and extends to 2009, the year the most recent mandate was passed. Probability weights are used to reflect the likelihood that each individual was sampled, as is standard in research using survey data. State and year fixed effects were included in each regression to control for the possibility of labor market shocks specific to any state or year.

\subsection{Discussion and Welfare Analysis}

Gruber (1992) developed a framework for the welfare analysis of a mandated benefit, which he applied to find that women put a value on maternity care coverage equal to its cost, a framework also used by Lahey (2012). Figure 3 demonstrates the idea. Mandates raise the total cost of compensating workers by $C$. The demand curve in terms of money wages for workers affected by the mandate will shift left by $C$, as in the case of a tax. This results in wages falling to $W_{2}$. If workers place no value on the mandate, then their labor supply curve remains the same, so the reduction in demand leads to employment falling to $L_{2}$. If instead workers value the mandate fully, their supply curve shifts right by the cost of the mandate $C$, balancing the shift in demand. This results in money wages falling to $W_{2}^{\prime}$, but hours worked remaining steady. If workers value the mandate at cost then welfare is unchanged from before the mandate. If workers value the mandate below its $\operatorname{cost} C$, welfare is reduced. The mandate functions like a tax equal to $(1-\alpha) * C$, where $\alpha$ is the worker's valuation of the mandate divided by its cost to employers. The left half of figure 3 represents the special case $\alpha=0$, while the right half represents the special case where $\alpha=1$.

With this theoretical framework in mind, the first question the empirical work answers is whether the mandate is large and binding enough to noticeably raise compensation costs, and so shift demand and lower money wages. This paper found that this is indeed the case for prostate cancer screening mandates, which lower the wages of men over age 50 by $2.8 \%$. The second question the empirical work can answer is how workers value the mandate and so what happens to welfare. If they value the mandate at its cost, then they perceive no change in the value of their compensation, only in how it is composed (more in health benefits and less in wages). However, if the workers value the mandated benefit at less than its cost, then the value of their total compensation has decreased (they lose more in wages than they gain in health benefits), and their hours worked and welfare decrease as a result.

The fact that there was a $2 \%$ decrease in the employment of men over age 50 after the passage of a mandate shows that workers do not value prostate cancer screening mandates at cost, and that welfare was reduced in their labor market. This, along with the significant reduction in employer-based health insurance coverage after a mandate, suggests that prostate cancer screen- 


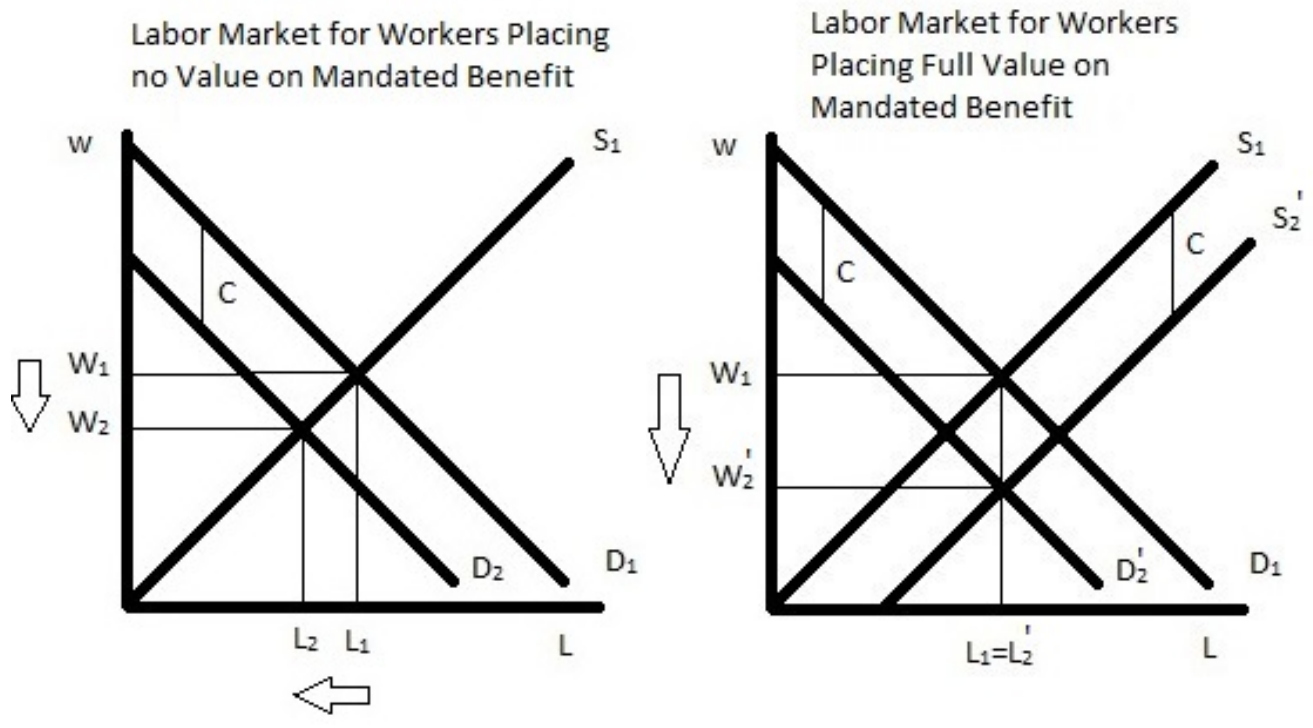

ing mandates are probably a poor policy, one which ends up hurting the very group it was intended to help.

However, there are two ways in which mandates could have better effects than these results seem to suggest. First, it is possible that men are incorrect to place such a low value on prostate cancer screening, and that the mandate actually improves their health enough to make them better off. But the medical research discussed in section 2 suggests otherwise: that men are probably correct in the low valuation they assign to screening. The mandates actually provide an excellent opportunity to study the disputed health effects of a marginal increase in screening; that question, however, is beyond the scope of this paper.

There is a second reason the broader welfare effects of the mandate may not be as bad as they may first appear, given the $2 \%$ drop in employment and the decrease in employer health insurance for men over age 50. The older men's jobs do not simply disappear; rather, so long as they are substitutes for other kinds of workers rather than complements, their place is taken by women and younger men. This paper found no significant effect of prostate cancer screening mandates on overall wages and employment for all workers (as measured by the coefficient of Mandate $_{s t}$ ), suggesting that men over 50 are in fact close substitutes for women and younger men.

The fact that other workers are substitutes for older men also helps to explain why the estimated effects of the mandate are so large. Difference-in-difference estimation does not measure the absolute change in the wages and employment of older men but rather the change relative 
to the comparison groups, the women and younger men whose wages and employment may increase following the mandate. The bulk of any negative welfare effect, then, likely comes from the decrease in the perceived value of compensation for the older men who kept their jobs, and from employers paying to make the transition to younger workers and women.

Further work using difference-in-difference estimation to study group-specific mandates must keep the possibility of complementary workers in mind. A paper could find no employment effect of mandates on the targeted group (as in Gruber (1994a)) either because there is no such effect, or because it is having an almost equal negative effect on the targeted workers and the complementary workers in the comparison group.

\subsection{Robustness}

\subsubsection{Comparison Group}

This paper's triple-difference analysis has compared men aged 50-64 to women aged 50-64 and to men aged 35-49. It is possible that the results are sensitive to the choice of comparison group. Age 65 was chosen as an upper bound because it is the age when eligibility for Medicare begins, and age 35 was chosen as a lower bound because it provides an age group spanning 15 years to mirror those 50-64. However, it is possible that younger people or people with Medicare actually are appropriate comparison groups. Alternatively, it is possible that the original analysis used too broad a range of ages to provide good control groups. A sensitivity analysis of the ages included is shown in Table 2. The estimated magnitudes of the coefficients experience moderate changes as new age groups are added or removed, but in each specification the effect of mandates on the labor market outcomes of older men remains significant. This suggests that the results are robust to various choices of comparison group.

\subsubsection{Serial Correlation}

Bertrand et al. (2004) describe how difference-in-difference estimation can lead to statistically significant results much more often than is appropriate due to failures to account for autocorrelation. In fact, they find that uncorrected autocorrelation in difference-in-difference estimation can lead to false positives in as many as $62.5 \%$ of regressions. The critiques raised by Bertrand et al. (2004) are highly relevant to this analysis, since their focus was on other papers which also use DD techniques on Current Population Survey data covering many time periods. In response, this paper has already taken several steps to avoid the pitfalls described by Bertrand et al. (2004). First and most obviously, this paper uses triple-difference rather than double-difference estimation, and so has several close control groups. Second, clustered standard errors were used to account for serial correlation of outcomes within states. Bertrand et al. (2004) found that using standard errors clustered on states (and therefore allowing an arbitrary variance-covariance matrix) reduces the proportion of false positive findings of significance to only $1.3 \%$. By using robust standard errors clustered on states, therefore, this paper deals with 
Table 2: Estimated Effect of Mandates on Older Men when Various Age Groups are Used

\begin{tabular}{cccc}
\hline & $\ln ($ HourlyWage $)$ & Employed & Employer Insures \\
\hline Ages 35-49, 50-64 & $-0.028^{* * *}$ & $-0.020^{* * *}$ & $-0.007 * * *$ \\
& $(0.010)$ & $(0.006)$ & $(0.003)$ \\
Ages 25-49, 50-64 & $-.036 * * *$ & $-.015 * * *$ & $-.009 * * *$ \\
& $(0.010)$ & $(0.006)$ & $(0.003)$ \\
Ages 40-49, 50-62 & $-.024 * * *$ & $-.020 * * *$ & $-.007 *$ \\
& $(0.008)$ & $(0.005)$ & $(0.004)$ \\
Ages 18-49, 50 and up & $-.037 * * *$ & $-.011 * *$ & $-.010 * * *$ \\
& $(0.011)$ & $(0.005)$ & $(0.003)$
\end{tabular}

*Indicates p-values less than $0.10 * *$ Indicates p-values less than $0.05 * * *$ Indicates p-values less than 0.01 ; Values in parentheses are robust standard errors clustered by state. The coefficients for $\ln$ (Hourly Wage) are the results of an Ordinary Least Squares regression. The numbers reported for Employment and Employer Insurance are the marginal effects from a Logit regression, since the dependent variables are binary. Coefficients of control variables (including demographic controls, state and year fixed effects, and the terms needed for triple differencing) are not shown. Person-level probability weights were used in all regressions to account for sampling bias.

the Bertrand et al. (2004) critique of difference-in-difference work and drastically reduces the probability that the significance of the results is merely due to chance.

\subsubsection{Endogeneity}

Table 3: Summary Statistics in 1990 for States Eventually Passing or Not Passing Mandate

\begin{tabular}{ccc}
\multicolumn{3}{c}{ Table 3: Summary Statistics in 1990 for States Eventually Passing or Not Pa } \\
\hline & $\begin{array}{c}\text { States with Mandate } \\
\text { (29 States and DC) }\end{array}$ & $\begin{array}{c}\text { States without Mandate } \\
\text { (21 states) }\end{array}$ \\
\hline Mean Age & 34.1 & 35.1 \\
Age 50-65 & $13.0 \%$ & $13.7 \%$ \\
Male & $48.7 \%$ & $48.6 \%$ \\
Mean Hourly Wage & $\$ 9.77$ & $\$ 9.56$ \\
Mean Income & $\$ 18,014$ & $\$ 16,959$ \\
Employer Insures & $82.4 \%$ & $80.5 \%$
\end{tabular}

Survey probability weights were used in calculations of means to account for sampling bias. Top-coded incomes were omitted in the calculation of mean income. Dollars are 1990 values unadjusted for inflation.

Another possible concern is with endogeneity. The estimation strategy of this paper effectively assumes that mandates were passed randomly. The estimates would be biased if the passage of mandates is in fact caused by the differences in the proportion of men over age 50 or in labor market outcomes across states. A simple, informal test of endogeneity is to look for systematic differences in demographics between states with and without mandates. The results 
of this comparison are shown in Table 3.

Overall, there seem to be small differences between the states that passed mandates and those that did not. States that passed mandates had a $1.9 \%$ higher rate of employer-based health insurance, which could indicate that more people in those states would benefit from a mandate. There is also a small difference in age between mandate and non-mandate states. However, the difference is in the opposite direction that one would expect if more people in the relevant interest groups lead states to pass mandates. States with prostate cancer mandates (which are intended to primarily benefit men over age 50 ) actually had a younger average population and fewer men age 50-65 as of 1990. It does not seem that demographic differences between states are large enough to cause major differences in the likelihood that a state would adopt a mandate. This informal comparison casts doubt on the possibility that endogeneity could be a major source of bias.

\begin{tabular}{cccc}
\hline & $\ln ($ HourlyWage $)$ & Employed & Employer Insures \\
\hline Male $*$ AgeGroup $*$ Mandate & $-.028^{* *}$ & $-.020^{* * *}$ & $-.007 * * *$ \\
& $(0.010)$ & $(0.006)$ & $(0.003)$ \\
Male $*$ AgeGroup & $.055^{* * *}$ & $-.030^{* * *}$ & $.011^{* * *}$ \\
& $(0.005)$ & $(0.004)$ & $(0.002)$ \\
Male $*$ Mandate & $-.018^{* * *}$ & $.012^{*}$ & -.002 \\
& $(0.006)$ & $(0.007)$ & $(0.003)$ \\
AgeGroup $*$ Mandate & .001 & $.021^{* * *}$ & $.013^{* * *}$ \\
& $(0.007)$ & $(0.004)$ & $(0.002)$ \\
Mandate & $.015^{* *}$ & -.007 & $-.006^{* *}$ \\
& $(0.007)$ & $(0.005)$ & $(0.003)$ \\
AgeGroup & $0.225^{* * *}$ & $-.313^{* * *}$ & $-.053^{* * *}$ \\
& $(0.019)$ & $(0.005)$ & $(0.005)$ \\
Male & $.271^{* * *}$ & $.131^{* * *}$ & $.015^{* * *}$ \\
& $(0.007)$ & $(0.004)$ & $(0.002)$ \\
State Fixed Effects & yes & yes & yes \\
Year Fixed Effects & yes & yes & yes \\
State-Specific Time Trends & yes & yes & yes \\
Observations & 803,409 & $1,299,581$ & 605,585 \\
\hline
\end{tabular}

Table 4: Results with State-Specific Time Trends

*Indicates p-values less than $0.10 * *$ Indicates p-values less than $0.05 * * *$ Indicates p-values less than 0.01; Values in parentheses are robust standard errors clustered by state. The coefficients for $\ln$ (Hourly Wage) are the results of an Ordinary Least Squares regression. The numbers reported for Employment and Employer Insurance are the marginal effects from a Logit regression, since the dependent variables are binary. Coefficients of demographic control variables are not shown (these include measures of age, race, ethnicity, education, and marital status for all regressions, as well as firm size and union membership in the wage and insurance regressions). The sample used is Americans aged 35-64. Person-level probability weights were used in all regressions to account for sampling bias. 
A slightly more formal method of assessing endogeneity is to include state-specific time trends in the main regressions, in addition to the state and year fixed effects already included. This allows for the fact that states may have already had a certain trend in wages, employment and employer-based health insurance before the passage of a mandate. Controlling for statespecific time trends should prevent the estimation from attributing to mandates what was really a pre-existing trend. The results of this exercise are shown in Table 4. The inclusion of statespecific time trends causes only very slight changes to the magnitude and significance of the coefficients.

Another way of investigating the potential endogeneity problem is to examine the leading and lagged effects of the mandate laws, as Autor (2003) did for unjust dismissal laws. Angrist and Pischke (2009) describe how to perform a kind of Granger test on a difference-in-difference specification. If the mandates are estimated to cause significant changes before they are actually adopted, it would suggest that the results found in this paper are simple pre-trends falsely attributed to the mandates. In general we expect causes to happen before effects, though it is possible that employers could respond today to prepare for a law they expect to be passed next year. Table 5 shows the estimated effects of mandates in the years before and after they are passed.

This test shows no significant evidence of a pre-trend where effects occur before their supposed cause, suggesting that there is no endogeneity problem nor any reaction in anticipation of the passage of a mandate. The test also shows that mandates have both an immediate and a persistent effect on employment. The estimated effect of the mandate on men over age 50 is significant in each year, and has a magnitude very close to the original estimate in the main specification. The test shows only a delayed effect on wages and insurance though, suggesting that they are somewhat sticky. The mandate has no significant effect on wages in the year it is passed or in the two years afterward, but does have a significant effect in the third and all subsequent years. 
Table 5: Leads and Lags Test

\begin{tabular}{|c|c|c|c|}
\hline & $\ln$ (HourlyWage) & Employed & Employer Insures \\
\hline \multirow[t]{2}{*}{ Male $*$ Age $*$ Mandate $_{t-2}$} & .005 & $.009 *$ & $.007 * *$ \\
\hline & $(0.017)$ & $(0.005)$ & $(0.004)$ \\
\hline \multirow{2}{*}{ Male $*$ Age $*$ Mandate $_{t-1}$} & .007 & .010 & .006 \\
\hline & $(0.017)$ & $(0.010)$ & $(0.006)$ \\
\hline \multirow[t]{2}{*}{${\text { Male } * \text { Age } * \text { Mandate }_{t}}$} & .012 & $-.019 * *$ & -.006 \\
\hline & $(0.017)$ & $(0.007)$ & $(0.006)$ \\
\hline \multirow[t]{2}{*}{ Male $*$ Age $*$ Mandat $_{t+1}$} & .018 & $-.016 * *$ & -.007 \\
\hline & $(0.017)$ & $(0.008)$ & $(0.006)$ \\
\hline \multirow[t]{2}{*}{ Male $*$ Age $*$ Mandate Mat $_{t+2}$} & -.008 & $-.021 * * *$ & $-.011 * *$ \\
\hline & $(0.019)$ & $(0.007)$ & $(0.005)$ \\
\hline \multirow[t]{2}{*}{ Male $*$ Age $*$ Mandat $_{t+3 \text { forward }}$} & $-.037 * * *$ & $-.019 * * *$ & $-.005 * *$ \\
\hline & $(0.011)$ & $(0.006)$ & $(0.003)$ \\
\hline
\end{tabular}

*Indicates p-values less than $0.10 * *$ Indicates p-values less than $0.05 * * *$ Indicates p-values less than 0.01; Values in parentheses are robust standard errors clustered by state. Law change dummies Male $*$ Age $*$ Mandate from $t-2$ to $t+2$ are equal to one for only one year each, but $t+3$ is equal to one in every year beginning with the third year after adoption. The coefficients for $\ln$ (Hourly Wage) are the results of an Ordinary Least Squares regression. The numbers reported for Employment and Employer Insurance are the marginal effects from a Logit regression, since the dependent variables are binary. Coefficients of control variables (including demographic controls, state and year fixed effects, and the terms needed for triple differencing) are not shown. Person-level probability weights were used in all regressions to account for sampling bias.

\section{Conclusion}

I find that prostate cancer mandates lead to statistically and economically significant declines in employment, wages, and insurance coverage for men over age 50. One lesson to take from this is that there are costs to health insurance benefit mandates, and that sometimes these costs fall precisely on those whom the mandate is intended to help. If mandated benefits increase costs to employers, they respond quickly by reducing other parts of the compensation package and substituting to mandate-exempt workers. A broader point is that prostate cancer mandates are one more example of labor market distortions caused by employer-provided health insurance. If health care were provided primarily through individual insurance, whether public or private, then mandates may result in inefficiently high medical spending but would not distort labor markets. But in the current US employer-based system, mandates may still lead to inefficiently high medical spending while also distorting labor markets. This paper demonstrates how prostate cancer mandates can distort the labor market for men over age 50. Prostate cancer treatment is only a small fraction of all medical care, but it demonstrates a general trend wherein employers are pushed away from any person or group predicted to have high health costs. 


\section{References}

Joshua Angrist and Jorn-Steffen Pischke. Mostly Harmless Econometrics. Princeton University Press, 2009.

David H. Autor. Outsourcing at will: The contribution of unjust dismissal doctrine to the growth of employment outsourcing. Journal of Labor Economics, 21(1):pp. 1-42, 2003. ISSN 0734306X. URL http://www.jstor.org/stable/10.1086/344122.

James Bailey. The effect of health insurance benefit mandates on premiums. Eastern Economic Journal, AOP:1-9, 2013. URL http://www .palgrave-journals. com/eej/journal/vaop/ncurrent/abs/eej201316a.html.

Marianne Bertrand, Esther Duflo, and Sendhil Mullainathan. How much should we trust differences-in-differences estimates? The Quarterly Journal of Economics, 119(1):249-275, 2004. doi: 10.1162/003355304772839588. URL http://qje. oxf ordjournals . org/content/119/1/249. abstract.

John Bound, Michael Schoenbaum, Todd R. Stinebrickner, and Timothy Waidmann. The dynamic effects of health on the labor force transitions of older workers. Labour Economics, 6(2):179 - 202, 1999. ISSN 0927-5371. doi: 10.1016/S0927-5371(99)00015-9. URL http://www.sciencedirect. com/science/article/pii/S0927537199000159.

Thomas C. Buchmueller, John DiNardo, and Robert G. Valletta. The effect of an employer health insurance mandate on health insurance coverage and the demand for labor: Evidence from hawaii. American Economic Journal: Economic Policy, 3(4):25-51, September 2011. doi: 10.1257/pol.3.4.25. URL http://www. aeaweb.org/articles.php?doi=10.1257/pol.3.4.25.

Victoria Craig Bunce and JP Wieske. Health insurance mandates in the states 2010. Technical report, Council for Affordable Health Insurance, 2011. URL http://www. cahi.org/cahi_contents/resources/pdf/MandatesintheStates2010.pdf.

Attila Cseh. Labor market consequences of state mental health parity mandates. Forum for Health Economics and Policy, 11(2): $1-32,2008$

Stephan F Gohmann and Myra McCrickard. The effect of state mandates on health insurance premiums. The Journal of Private Enterprise, 24(2):59-73, 2009. URL ht tp: //journal . apee . org/index . php?t itle=Spring2009_5.

Jonathan Gruber. The efficiency of a group-specific mandated benefit: Evidence from health insurance benefits for maternity. Working Paper 4157, National Bureau of Economic Research, September 1992. URL http: //www. nber.org/papers/w4157.

Jonathan Gruber. The incidence of mandated maternity benefits. The American Economic Review, 84(3):pp. 622-641, 1994a. ISSN 00028282. URL http://www.jstor.org/stable/2118071.

Jonathan Gruber. State-mandated benefits and employer-provided health insurance. Journal of Public Economics, 55(3):433 - 464, 1994b. ISSN 0047-2727. doi: 10.1016/0047-2727(93)01407-2. URL http://www.sciencedirect.com/science/article/pii/0047272793014072.

N Howlader, AM Noone, M Krapcho, J Garshell, N Neyman, SF Altekruse, CL Kosary, M Yu, J Ruhl, Z Tatalovich, H Cho, A Mariotto, DR Lewis, HS Chen, EJ Feuer, and KA Cronin. Seer cancer statistics review, 1975-2010. Technical report, National Cancer Institute, 2013. URL http://seer.cancer.gov/csr/1975_2010/.

Bruce L. Jacobs, Yun Zhang, Ted A. Skolarus, and Brent K. Hollenbeck. Growth of high-cost intensity-modulated radiotherapy for prostate cancer raises concerns about overuse. Health Affairs, 31(4):750-759, 2012. doi: 10.1377/hlthaff.2011.1062. URL http://content . heal thaffairs.org/content/31/4/750 . abstract.

Gail A. Jensen and Jon R. Gabel. State mandated benefits and the small firm's decision to offer insurance. Journal of Regulatory Economics, 4:379-404, 1992. ISSN 0922-680X. URL http://dx.doi.org/10.1007/BF00134929. 10.1007/BF00134929.

Gail A. Jensen and Michael A. Morrisey. Employer-sponsored health insurance and mandated benefit laws. The Milbank Quarterly, 77(4):pp. 425-459, 1999. ISSN 0887378X. URL http://www. jstor. org/stable/3350570.

Robert Kaestner and Kosali Ilayperuma Simon. Labor market consequences of state health insurance regulation. Industrial and Labor Relations Review, 56(1):pp. 136-159, 2002. ISSN 00197939. URL http://www.jstor.org/stable/3270653.

Miriam King, Steven Ruggles, J. Trent Alexander, Sarah Flood, Katie Genadek, Matthew B. Schroeder, Brandon Trampe, and Rebecca Vick. Integrated public use microdata series, current population survey: Version 3.0. [machine-readable database]. Technical report, Minneapolis: University of Minnesota, 2010. URL http://cps. ipums.org/cps/index.shtml.

Amanda E. Kowalski, William J. Congdon, and Mark H. Showalter. State health insurance regulations and the price of high-deductible policies. Forum for Health Economics \& Policy, 11(2):8, 2008. URL http://ideas.repec.org/a/bpj/fhecpo/v11y2008i2n8.html.

Joanna N. Lahey. The efficiency of a group-specific mandated benefit revisited: The effect of infertility mandates. Journal of Policy Analysis and Management, 31(1):63-92, 2012. ISSN 1520-6688. doi: 10.1002/pam.20616. URL http://dx.doi.org/10.1002/pam.20616.

Tracey A. LaPierre, Christopher J. Conover, James W. Henderson, J. Allen Seward, and Beck A. Taylor. Estimating the 
impact of state health insurance mandates on premium costs in the individual market. Journal of Insurance Regulation, 27(3):3 - 36, 2009. ISSN 0736248X.

Susan Laudicina, Joan Gardner, and Kim Holland. State legislative healthcare and insurance issues. Technical report, Blue Cross Blue Shield Association, 2011.

Jonathan Meer and Jeremy West. Identifying the effects of health insurance mandates on small business employment and pay. Technical report, Texas A\&M, 2011. URL http: //econweb.tamu.edu/jmeer/Meer_West_Mandates_111130.pdf.

Jean M. Mitchell. Urologists' self-referral for pathology of biopsy specimens linked to increased use and lower prostate cancer detection. Health Affairs, 31(4):741-749, 2012. doi: 10.1377/hlthaff.2011.1372. URL http: //content .healthaffairs . org/content/31/4/741.abstract.

Alan C. Monheit and Jasmine Rizzo. Mandated health insurance benefits: A critical review of the literature. Technical report, New Jersey Department of Human Services, $2007 . \quad$ URL http://www. cshp.rutgers.edu/Downloads/7130.pdf.

Charles Roehrig, George Miller, Craig Lake, and Jenny Bryant. National health spending by medical condition, 1996-2005. Health Affairs, 28(2):358-367, 2009. doi: 10.1377/hlthaff.28.2.w358. URL http: //content.healthaffairs .org/content/28/2/w358. abstract.

Frank A. Scott, Mark C. Berger, and John E. Garen. Do health insurance and pension costs reduce the job opportunities of older workers? Industrial and Labor Relations Review, 48(4):pp. 775-791, 1995. ISSN 00197939. URL http://www.jstor.org/stable/2524356.

Lawrence H. Summers. Some simple economics of mandated benefits. The American Economic Review, 79(2):pp. 177-183, 1989. ISSN 00028282. URL http://www.jstor.org/stable/1827753.

USPSTF. Screening for prostate cancer: Final recommendation statement. Technical report, U.S. Preventive Services Task Force, 2012. URL http: //www .usprevent iveservicestaskf orce.org/prostatecancerscreen ing/prostatef inalrs.htm.

David N Van der Goes, Justin Wang, and Katharine C Wolchik. Effect of state health insurance mandates on employer-provided health insurance. Eastern Economic Journal, 37(4):437-449, 2011. ISSN 00945056. URL http://www.palgrave-journals . com/eej/journal/v37/n4/abs/eej200950a.html. 